\title{
ANALISIS ANGKA SEKSIO CAESAREA DI RSUP DR SARDJITO YOGYAKARTA TAHUN 2009-2013
}

\author{
Netty Katrina, Djaswadi Dasuki, Rukmono Siswishanto
}

\begin{abstract}
Background: Caesarean section is a procedure to reduce maternal and perinatal mortality and morbidity. The caesarean section rate is continuously uprising in the last 3 decades. However, the increasing rate, especially in low risk women, may compromise maternal and perinatal outcome. In 1985, WHO recommended that optimal national caesarean rates should be in the range of $5 \%$ to $10 \%$ and the rate above $15 \%$ might be less benefits. Previous study conducted in DR Sardjito hospital reported caesarean section rate in 1996 was 13.38\%, while in 2001 was 18.39\%. In national level, based on Indonesia Basic Health Survey 2010, caesarean section rate was $10.8 \%$. Therefore, in this study we analyzed the rate of Caesarean section performed in DR Sardjito hospital, and studied whether the operations occurred in high-risk group or low-risk group.

Objective: To compare the rate of caesarean section between high-risk group and low-risk group in DR Sardjito hospital

Method: Retrospective cohort

Result and Discussion: Participants of this study were 7821 patients undergoing labor at RSUP DR Sardjito in 2009-2013. Among them, 3152 patients underwent caesarean section and 4669 patients underwent vaginal delivery. There was an increasing in the overall caesarean section rate of $38,7 \%$ in 2009 to $43 \%$ in 2013. T-test found the presence of significant differences between the caesarean section rate of high-risk group and low-risk group in 2009-2013 $(p<0.05)$ with a mean difference was 28.5 (20.2-36.8). Caesarean section rate of high-risk group was significantly higher than the low-risk group $(p<0.05)$.

Conclusion: There was a difference in caesarean section rate of high-risk group compared to low-risk group. Caesarean section rate in high-risk group was significantly higher than in the low-risk group.
\end{abstract}

Keywords: caesarean section rate, caesarean section, low-risk group, high- risk group

\begin{abstract}
ABSTRAK
Latar Belakang: Seksio caesarea adalah tindakan yang dilakukan dalam usaha menurunkan mortalitas dan morbiditas ibu dan janin. Hal ini menyebabkan angka seksio caesarea di seluruh dunia semakin meningkat dalam 3 dekade terakhir. Namun adanya peningkatan angka seksio caesarea secara global terutama pada pasien dengan risiko rendah berdampak sebaliknya. Pada tahun 1985, WHO merekomendasikan angka seksio caesarea antara 5-10\%, diatas 15\% lebih banyak berakibat buruk dibanding keuntungannya. Penelitian yang dilakukan di RSUP DR. Sardjito, angka seksio caesarea pada tahun 1996 adalah 13,38\%, dan tahun 2001 menjadi 18,39\%. Berdasarkan data Riset Kesehatan Dasar RI angka seksio caesarea di Indonesia sebesar 10,8 \%. Apakah tingginya seksio caesarea di RSUP Dr Sardjito terjadi pada kelompok risiko tinggi atau kelompok risiko rendah, menjadi perhatian pada penelitian ini.
\end{abstract}

Departemen Obstetri dan Ginekologi, Fakultas Kedokteran Universitas Gadjah Mada/

RSUP Dr. Sardjito Yogyakarta 
Tujuan: mengetahui angka seksio caesarea di RSUP DR Sardjito dari tahun 2009-2013 dan pada kelompok manakah terjadi angka seksio caesarea yang tinggi.

Metode: kohort retrospektif

Hasil dan Pembahasan: Subyek penelitian ini adalah pasien yang menjalani persalinan di RSUP DR Sardjito Yogyakarta dari tahun 2009-2013 yaitu sebanyak 7821 orang. Pasien yang menjalani seksio caesarea adalah sebanyak 3152 orang dan yang menjalani persalinan vaginal sebanyak 4669 orang. Selama 5 tahun telah terjadi peningkatan angka seksio caesarea keseluruhan dari tahun 2009 yaitu 38,7\% menjadi 43\% di tahun 2013. Dari uji T didapatkan adanya perbedaan bermakna angka seksio caesarea antara kelompok risiko tinggi dibandingkan kelompok risiko rendah dari tahun 2009-2013 $(\mathrm{p}<0,05)$ dengan perbedaan rerata $28,5(20,2-36,8)$. Angka seksio caesarea pada kelompok risiko tinggi, lebih tinggi secara bermakna dibandingkan kelompok risiko rendah $(p<0,05)$.

Kesimpulan: terdapat perbedaan angka seksio caesarea pada kelompok risiko tinggi dibanding dengan kelompok risiko rendah, dimana kelompok risiko tinggi mempunyai angka seksio caesarea yang lebih tinggi secara bermakna.

Kata kunci: angka seksio caesarea, seksio caesarea, kelompok risiko rendah, kelompok risiko tinggi

\section{PENDAHULUAN}

Angka seksio caesarea di seluruh dunia semakin meningkat dalam 3 dekade terakhir. Seksio caesarea menjadi prosedur operatif yang paling sering dilakukan. Pada tahun 1985, WHO merekomendasikan angka seksio caesarea antara $5-10 \%$, diatas $15 \%$ lebih banyak berakibat buruk dibanding keuntungannya. Namun angka seksio caesarea seluruh dunia dari sekitar $5 \%$ di negara-negara maju pada awal 1970 menjadi sekitar 50\% pada akhir tahun $1990^{1}$ Pada tahun 2005, WHO juga melakukan penelitian dengan membagi wanita hamil dalam beberapa kelompok berdasarkan indikasi obstetri untuk mengidentifikasi seksio caesarea yang dapat dicegah tanpa membahayakan ibu hamil dan janin, dan menemukan 2 kelompok yang memiliki kontribusi terbesar dari seluruh angka seksio caesarea yaitu kelompok wanita hamil yang menjalani induksi persalinan dan wanita dengan riwayat seksio caesarea sebelumnya.

Tujuan penelitian ini adalah mengetahui angka seksio caesarea di RSUP DR Sardjito dari tahun 2009 sampai dengan tahun 2013 dan menganalisis tingkat seksio caesarea kelompok risiko tinggi dan kelompok risiko rendah pada ibu hamil di RSUP DR.Sardjito dari tahun 2009 sampai dengan tahun 2013.

\section{METODE}

Penelitian dilakukan secara observasional dengan metode kohort retrospektif yang menganalisis angka seksio caesarea pada berbagai kelompok risiko.

Populasi penelitian adalah semua pasien yang bersalin di RSUP DR Sardjito pada tahun 2009-2013. Kriteria eksklusi adalah semua pasien yang bersalin dengan janin meninggal atau kelainan.

Seluruh populasi akan dipisahkan berdasarkan kriteria inklusi dan eksklusi kemudian digolongkan menurut kelompok risiko dan kelompok karakteristik obstetri berdasarkan survei yang dilakukan WHO tahun 2005.

Variabel bebas adalah kelompok risiko berdasarkan karakteristik obstetri wanita hamil ketika dilakukan seksio caesarea (karakteristik 
obstetri 1-6). Variabel tergantung adalah seksio caesarea dan variabel luar adalah usia ibu dan berat badan bayi.

Uji t digunakan untuk membandingkan angka seksio caesarea antara tiap kelompok risiko. Uji Chi-square digunakan untuk membandingkan variabel luar antara 2 kelompok risiko, kejadian seksio caesarea antara 2 kelompok risiko dan hubungan antara variabel luar dengan kejadian seksio caesarea. Analisis multivariat digunakan untuk mengetahui hubungan antara variabel bebas dan variabel tergantung secara bersamasama dengan mengendalikan variabel luar. Pengaruh variabel-variabel ini dianalisis dengan uji statistik analisis regresi logistik.

\section{HASIL DAN PEMBAHASAN}

Pasien yang menjalani persalinan di RSUP DR Sardjito Yogyakarta dari tahun 2009-2013 yaitu sebanyak 7821 orang. Pasien yang menjalani seksio caesarea adalah sebanyak 3152 orang dan yang menjalani persalinan vaginal sebanyak 4669 orang. Gambaran tentang karakteristik subyek penelitian dijelaskan dalam bentuk distribusi frekuensi berdasarkan variabel dalam penelitian.

Dari penelitian ini didapatkan peningkatan angka seksio caesarea keseluruhan dari tahun 2009 yaitu 38,7\% menjadi 43\% di tahun 2013 (lihat Gambar 1). Kelompok berdasarkan risiko yang paling banyak dilakukan seksio caesarea adalah pada kelompok kritis. Nampak adanya kecenderungan peningkatan yang besar dari tahun 2009 (53\%) sampai tahun 2013 (72,2\%). Kelompok risiko tinggi cenderung menetap proporsinya, sedangkan yang menarik kelompok risiko rendah mengalami penurunan tajam di tahun 2012.

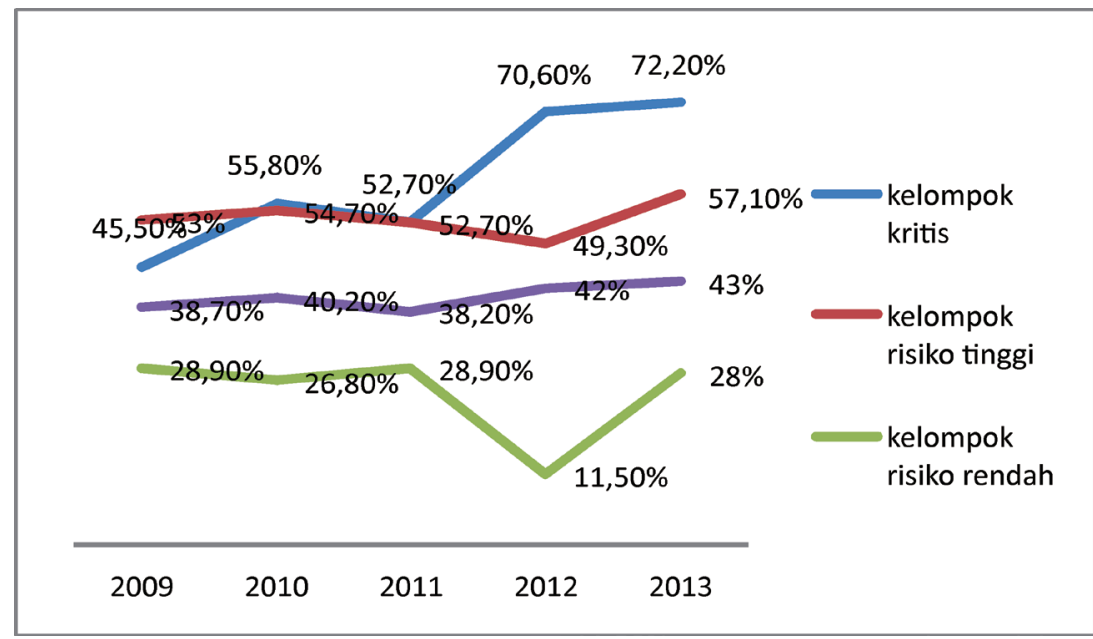

\section{GAMBAR I. Rate Seksio Caesarea Keseluruhan dan Rate Seksio Caesarea pada Tiap Kelompok Risiko di RSUP DR Sardjito dari Tahun 2009-2013}

Bila dicermati nampak pada gambar II, bahwa penyumbang terbesar angka seksio caesarea pada kelompok kritis ini adalah dari kelompok yang memiliki riwayat seksio caesarea sebelumnya, yaitu dari $73,7 \%$ (tahun 2009) menjadi 90\% (tahun 2013). Pada tahun 2012, kelompok pasien yang menjalani induksi mengalami lonjakan kenaikan angka seksio caesarea. 


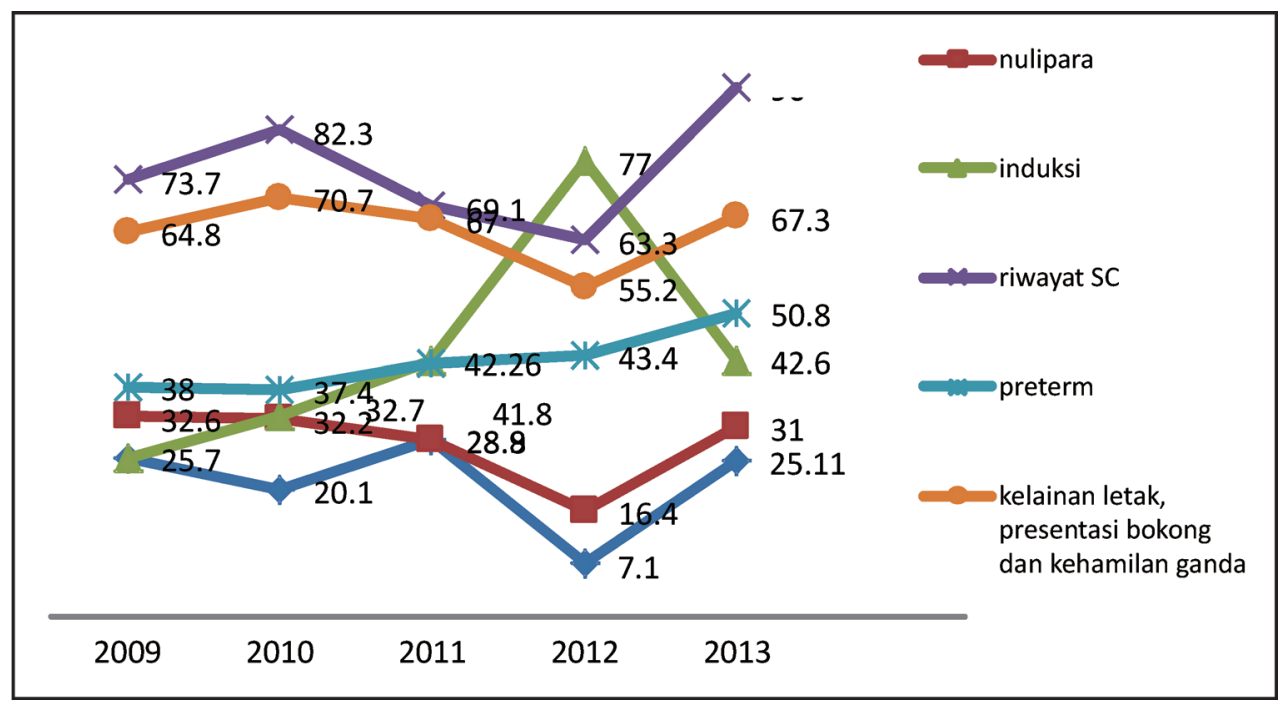

GAMBAR 2. Rate Seksio Caesarea pada Tiap Kelompok

Kelompok berikutnya yang paling sering dilakukan seksio caesarea adalah kelompok risiko tinggi yaitu pasien yang memiliki kelainan letak, presentasi bokong dan kehamilan ganda yaitu dari tahun 2009 sebanyak 64,8\% menjadi 67,3\% di tahun 2013. Kelompok yang paling sedikit dilakukan seksio caesarea adalah kelompok dengan risiko rendah. Pada kelompok ini nampak bahwa pasien nulipara lebih banyak dilakukan seksio caesarea dibandingkan kelompok multipara.
Terdapat perbedaan bermakna angka seksio caesarea antara kelompok risiko tinggi dibandingkan kelompok risiko rendah $(p<0,05)$. Perbandingan subyek pada kelompok risiko tinggi dan kelompok risiko rendah terhadap variabel luar yaitu usia ibu dan berat badan bayi yang dilahirkan dari tahun 2009-2013 mayoritas memiliki perbedaan bermakna $(p<0,05)$. Analisis angka seksio caesarea dari tahun 2009-2013 antara kelompok risiko tinggi dan risiko rendah ditunjukkan pada tabel 1. 
Tabel 1. Karakteristik Subyek dan Komparabilitas antara Kelompok Risiko Tinggi dan Kelompok Risiko Rendah

\begin{tabular}{|c|c|c|c|c|c|c|}
\hline \multirow{2}{*}{$\begin{array}{l}\text { Tahun } \\
2009\end{array}$} & \multirow{2}{*}{$\begin{array}{ll} & \text { Variabel } \\
\text { Usia ibu }\end{array}$} & \multicolumn{2}{|c|}{ Kelompok risiko } & \multirow[t]{2}{*}{$P$} & \multirow[t]{2}{*}{$\mathrm{RR}$} & \multirow[t]{2}{*}{$\mathrm{Cl}$} \\
\hline & & Tinggi & Rendah & & & \\
\hline & $\geq 35$ tahun & $126(27,0 \%)$ & $209(23,2 \%)$ & 0,120 & 1,14 & $0,96-1,34$ \\
\hline & $<35$ tahun & $340(73,0 \%)$ & $691(76,8 \%)$ & & & \\
\hline & Berat badan lahir bayi & & & & & \\
\hline & $<z 2500$ gram dan $\geq 4000$ gram & $299(64,2 \%)$ & $114(12,7 \%)$ & 0,000 & 4,13 & $3,55-4,80$ \\
\hline & 2500-3999gram & $167(35,8 \%)$ & $786(87,3 \%)$ & & & \\
\hline \multirow[t]{6}{*}{2010} & Usia ibu & & & & & \\
\hline & $\geq 35$ tahun & $159(31,1 \%)$ & $194(21,6 \%)$ & 0,000 & 1,34 & $1,16-1,55$ \\
\hline & $<35$ tahun & $353(68,9 \%)$ & $703(78,4 \%)$ & & & \\
\hline & Berat badan lahir bayi & & & & & \\
\hline & <z 2500 gram dan $\geq 4000$ gram & $257(55,5 \%)$ & $83(9,3 \%)$ & 0,000 & 3,74 & $3,26-4,28$ \\
\hline & 2500-3999gram & $206(44,5 \%)$ & $814(90,7 \%)$ & & & \\
\hline \multirow[t]{6}{*}{2011} & Usia ibu & & & & & \\
\hline & $\geq 35$ tahun & $136(26,8 \%)$ & $237(22,9 \%)$ & 0,089 & 1,15 & $0,98-1,34$ \\
\hline & $<35$ tahun & $371(73,2 \%)$ & $799(77,1 \%)$ & & & \\
\hline & Berat badan lahir bayi & & & & & \\
\hline & $<2500$ gram dan $\geq 4000$ gram & $367(72,4 \%)$ & $116(11,2 \%)$ & 0,000 & 5,75 & $4,89-6,76$ \\
\hline & 2500-3999gram & $140(27,6 \%)$ & $920(88,8 \%)$ & & & \\
\hline \multirow[t]{6}{*}{2012} & Usia ibu & & & & & \\
\hline & $\geq 35$ tahun & $132(28,8 \%)$ & $59(17,0 \%)$ & 0,000 & 1,30 & $1,15-1,47$ \\
\hline & $<35$ tahun & $326(71,2 \%)$ & $289(83,0 \%)$ & & & \\
\hline & Berat badan lahir bayi & & & & & \\
\hline & $<2500$ gram dan $\geq 4000$ gram & $266(58,1 \%)$ & $31(8,9 \%)$ & 0,000 & 2,37 & $2,11-2,67$ \\
\hline & 2500-3999 gram & $192(41,9 \%)$ & $317(91.1 \%)$ & & & \\
\hline \multirow[t]{6}{*}{2013} & Usia ibu & & & & & \\
\hline & $\geq 35$ tahun & $137(28,8 \%)$ & $161(17,4 \%)$ & 0,000 & 1,49 & $1,28-1,73$ \\
\hline & $<35$ tahun & $339(71,2 \%)$ & $762(82,6 \%)$ & & & \\
\hline & Berat badan lahir bayi & & & & & \\
\hline & $<2500$ gram dan $\geq 4000$ gram & $369(77,5 \%)$ & $99(10,7 \%)$ & 0,000 & 6,86 & $5,70-8,24$ \\
\hline & 2500-3999 gram & $107(22,5 \%)$ & $824(89,3 \%)$ & & & \\
\hline
\end{tabular}

Pada analisis multivariabel dari tahun 20092013, nampak bahwa yang paling berpengaruh bermakna $(p<0.05)$ terhadap kejadian seksio caesarea adalah kelompok risiko dengan OR antara 3,20-7,50 (tabel 2). 
Tabel 2. Hubungan Kejadian Seksio Caesarea dengan Kelompok Risiko setelah Mengontrol Usia ibu dan Berat Badan Bayi

\begin{tabular}{lccccc}
\hline \multirow{2}{*}{ Variabel } & \multicolumn{5}{c}{ OR(IK95\%) } \\
\cline { 2 - 6 } & $\mathbf{2 0 0 9}$ & $\mathbf{2 0 1 0}$ & $\mathbf{2 0 1 1}$ & $\mathbf{2 0 1 2}$ & $\mathbf{2 0 1 3}$ \\
\cline { 2 - 6 } & 3.20 & 3,50 & 3.57 & 7.50 & 3,31 \\
\hline Kelompok risiko & $(2.42-4,23)$ & $(2,65-4,63)$ & $(2,66-4,79)$ & $(5,14-10.93)$ & $(2,62-4,19)$ \\
& $\mathbf{1 . 3 2}$ & $\mathbf{1 , 3 5}$ & $\mathbf{1 , 7 7}$ & 1,03 & $\mathbf{1 , 4 3}$ \\
Usia ibu & $\mathbf{( 1 , 0 1 - 1 , 7 1 )}$ & $\mathbf{( 1 , 0 4 - 1 , 7 5 )}$ & $\mathbf{( 1 , 3 8 - 2 , 2 6 )}$ & $(0.71-1.49)$ & $\mathbf{( 1 , 0 9 - 1 , 8 8 )}$ \\
Berat badan bayi & 0.75 & $\mathbf{0 , 7 1}$ & 0,64 & 0,77 & 1,01 \\
& $(0,56-1.00)$ & $\mathbf{( 0 , 5 6 - 0 , 9 7 )}$ & $(0,47-0.87)$ & $(0,54-1.10)$ & $(0,74-1,39)$ \\
Konstanta & 0,39 & 0,35 & 0,36 & 0,13 & 0,36 \\
\hline
\end{tabular}

Pada penelitian ini terdapat peningkatan angka seksio caesarea dari tahun 2009 yaitu $38,7 \%$ menjadi $43 \%$ di tahun 2013. Penelitian yang dilakukan di RSUP DR. Sardjito, angka seksio caesarea pada tahun 1996 adalah 13,38\%, dan tahun 2001 adalah 18,39\%. Setelah dilakukan uji t didapatkan adanya perbedaan bermakna angka seksio caesarea antara kelompok risiko tinggi dibandingkan kelompok risiko rendah $(p<0,05)$.

Pada beberapa penelitian menunjukkan adanya hubungan terbalik antara angka seksio caesarea dengan mortalitas ibu dan bayi pada daerah dengan pendapatan rendah dimana sebagian besar penduduknya kesulitan akses pada pelayanan dasar obstetrik. ${ }^{2}$ Sedangkan di lain pihak angka seksio caesarea di atas limit tampaknya tidak menunjukkan keuntungan bagi ibu dan bayi bahkan beberapa penelitian menunjukkan adanya konsekuensi negatif.

Setelah mengontrol usia ibu dan berat badan bayi, kelompok risiko merupakan yang paling berpengaruh terhadap kejadian seksio caesarea dengan OR 3,20-7,50. Prediktor lain yang berpengaruh secara bervariasi terhadap terjadinya seksio caesarea pada penelitian ini adalah faktor usia ibu. Myometrium ternyata tidak imun terhadap peningkatan usia. Penuaan berkontribusi terhadap melemahnya myometrium sehingga menimbulkan lebih seringnya dilakukan seksio caesarea. ${ }^{3}$ Usia yang lebih tua juga berhubungan dengan kecemasan tentang fertilitas yang semakin menurun. Meningkatnya usia ibu akhirnya mempengaruhi pengambilan keputusan mengenai cara persalinan. ${ }^{4}$

\section{Kelompok risiko rendah}

Angka seksio caesarea pada kelompok risiko rendah dari tahun 2009-2013 cenderung stabil dari $28,9 \%$ menjadi $28 \%$.

Angka seksio caesarea pada kelompok risiko rendah ini tidak jauh berbeda dengan angka seksio caesarea yang terjadi di negara maju dan di negara berkembang seperti India $(21,4 \%)$ pada tahun 2007. ${ }^{5}$ WHO menganjurkan angka seksio caesarea optimal adalah tidak melebihi $15 \%$ mengingat risiko yang akan terjadi pada ibu dan bayi. Seksio caesarea pada kelompok risiko rendah berhubungan dengan morbiditas neonatal yang lebih tinggi disertai mortalitas dan morbiditas ibu yang lebih tinggi. 6,7

\section{Kelompok risiko tinggi}

Angka seksio caesarea pada kelompok risiko tinggi terjadi peningkatan dari tahun 2009 yaitu 45,5\% menjadi 57,1\% pada tahun 2013. 
Penyumbang terbanyak angka seksio caesarea pada kelompok ini adalah kelompok kelainan letak, presentasi bokong dan kehamilan ganda yaitu dari tahun 2009-2013 berfluktuasi antara $55,2 \%-67,3 \%$.

Angka seksio caesarea pada presentasi bokong yang optimal sekitar $30 \%-60 \%$, namun hal ini bervariasi sesuai keinginan pasien. Beberapa negara, angka seksio caesarea pada presentasi bokong adalah 80\%. Dalam 2 buah penelitian meta analisis menunjukkan risiko kematian perinatal yang berhubungan dengan persalinan vaginal 2-5 kali lebih tinggi dibandingkan dengan seksio caesarea terencana. Kematian bayi dengan presentasi bokong antara usia kehamilan 3336 minggu sangat jarang dan tidak dipengaruhi oleh cara persalinan. Namun usia kehamilan 26 minggu-32 minggu lah yang sangat berbahaya. ${ }^{8}$

Pada kehamilan ganda, cara persalinan masih kontroversial. Kebanyakan tergantung pada korionisitas, adanya komplikasi fetal dan maternal, usia kehamilan dan presentasi kedua janin pada saat persalinan.

Terdapat beberapa RCT mengenai cara persalinan terbaik. Pada suatu RCT dikatakan tidak terdapat perbedaan bermakna persalinan vaginal maupun seksio caesarea pada kehamilan ganda usia kehamilan $\geq 35$ minggu dengan bayi pertama presentasi kepala dan bayi kedua presentasi bukan kepala. Disarankan seksio caesarea adalah kehamilan ganda dimana janin pertama dengan presentasi bukan kepala karena dikhawatirkan terjadi inter-locking. Pada kehamilan ganda dengan kedua janin presentasi kepala dianjurkan cara persalinan adalah persalinan vaginal. ${ }^{9}$

\section{Kelompok kritis}

Angka seksio caesarea pada kelompok ini mengalami peningkatan dari 53\% menjadi $72,2 \%$. Kelompok kritis terdiri dari wanita yang menjalani induksi persalinan; dan wanita dengan usia kehamilan $\geq 37$ minggu aterm. Upaya untuk menurunkan angka seksio caesarea pada kelompok induksi pernah dilakukan pada sebuah penelitian yang melibatkan 300 partisipan dimana induksi dilakukan sebagai tindakan preventif yaitu pada usia kehamilan 38-41 minggu. Managemen akif ditawarkan pada pasien untuk dilakukan induksi mencegah bayi terlalu besar saat dilahirkan dan semakin tuanya plasenta untuk menunjang kesejahteraan janin saat persalinan. Usia kehamilan minimal 38 minggu ditentukan berdasarkan pemeriksaan USG awal kehamilan untuk mencegah gangguan pernafasan pada bayi dan direncanakan semaksimal mungkin lahir 1-3 hari sebelum usia kehamilan 41 minggu. Penelitian ini terbukti secara bermakna dapat menurunkan angka seksio caesarea tanpa luaran yang buruk pada bayi. ${ }^{10}$

Angka seksio caesarea pada kelompok yang memiliki riwayat seksio caesarea dari tahun 2009-2013 berfluktuasi antara 63,3\%$90 \%$. Kelompok ini merupakan penyumbang angka seksio caesarea terbanyak. Hal ini dapat menunjukkan bahwa tingginya angka seksio caesarea di RSUP DR Sardjito dikarenakan RSUP Dr. Sardjito merupakan pusat rujukan. Kelompok dengan riwayat seksio caesarea sebelumnya merupakan kontributor utama peningkatan angka seksio caesarea. Terdapat risiko serius dan signifikan walaupun jarang yang berhubungan dengan VBAC maupun seksio caesarea ulangan. ${ }^{11}$ Sehingga perlu dilakukan monitoring ketat dan edukasi pasien tentang kemungkinan kemungkinan yang dapat terjadi.

\section{KESIMPULAN DAN SARAN}

Angka seksio caesarea di RSUP DR Sardjito dari tahun 2009-2013 mengalami peningkatan, dari tahun 2009 yaitu 38,7\% menjadi $43 \%$ di tahun 2013. Angka seksio caesarea pada kelompok risiko tinggi, lebih tinggi secara bermakna dibandingkan dengan kelompok risiko rendah. 
Menindaklanjuti penelitian ini perlu dilakukan penelitian mengenai luaran ibu dan bayi pada masing-masing kelompok risiko untuk menilai apakah angka seksio caesarea di RSUP DR Sardjito sudah tepat.

\section{DAFTAR PUSTAKA}

1. Penn Z, Maghami SG. 2001. Indications for Caesarean Section, Best Practice \& Research Clinical Obstetrics \&Gynaecology, 15:1-11.

2. Litorp H, Kidanto HL, Nystrom L, Darj E, Essen B. 2013. Increasing Caesarean Section among LowRisk Group: a Panel Study Classifying Deliveries according to Robson at a University Hospital in Tanzania, BMC Pregnancy and Childbirth, 13:107.

3. Denise M, Elliot KM, Dan HM. 2000. The Relationship Between Maternal Age and Uterine Dysfunction: A Continuous Effect throughout Reproductive Life, Am J Obstet Gynecol ; 182:1312-20

4. Michelle JK, Osterman MHS, Joyce AM. 2013. Changes in Cesarean Delivery rate by Gestasional Age: United States, 1996-2011 ,NCHS Data Brief No. 124

5. Tamim H, El-Chemaly SY, Nassar AH, Campbell OM, Afamia AK, Khalid AY, 2007. Cesarean Delivery Among Nulliparous Women in Beirut: Assessing Predictors in Nine Hospitals for the National
Collaborative Perinatal Neonatal Network, Birth; 34:14-20

6. Hawkins JL, Koonin LM, Palmer SK, Gibbs CP. 1997. Anesthesia-Related Deaths During Obstetric Delivery in The United States, 1979-1990, The Journal of The American Society of Anesthesiologists, 86:277-284

7. Liu S, Liston RM, Joseph KS, Heaman M, Sauve R, Krame MS, 2007. Maternal Mortality and Severe Morbidity associated with Low-Risk Planned Cesarean Delivery versus Planned Vaginal Deliveryat Term, Canadian Medical Association,176:455-460.

8. Anonim, 2013. Care of Women With Breech Presentation or Previous Caesarean Birth, New England Guidelines Group Bests Practice Evidence Based Guidelines.

9. Barrett JFR, Ritchie WK. 2002. Twin Delivery. Best Practice \& Research Clinical Obstetrics and Gynaecology, 16: 43-56

10. Nicholson JM, Cronholm P, Kellar LC, Stenson MH, Macones GA. 2009. The Association between Increased Use of Labor Induction and Reduced rate of Cesarean Delivery, Journal of Women's Health,Vol 18:11

11. RCOG Green-top Guideline, 2007. Birth After Previous Caesarean Birth, RCOG Green-top Guideline; 45:1-17 